\title{
United Kingdom Culture Collections
}

\author{
By S. T. COWAN \\ National Collection of Type Cultures, Colindale, London, N.W.9
}

SUMMARY : Old catalogues are useless in trying to locate micro-organisms in culture collections. The addresses are given of the larger culture collections in the U.K., and an indication of the type of micro-organisms each maintains.

Specialized collections exist in different parts of the country, but in the past few have undertaken to distribute cultures except as a personal favour to colleagues working on similar problems. The chief difficulty of those seeking cultures is to know where to write, and what cultures are available. There have been so many changes in the organisms kept in the different collections that pre-war catalogues give no indication of the present whereabouts of the various species. It may be helpful to indicate where different types of micro-organism are now kept.

Algae and Protozoa. Algae, flagellata and ciliosa are kept in Dr E. G. Pringsheim's collection at Cambridge (Collection 1 in Table 1). When application is made for a culture the intended use should be indicated so that the culture may be brought into the appropriate state.

Other laboratories keep Protozoa of interest to medical and veterinary workers, and the addresses can be found in a mimeographed catalogue prepared by the Laboratory Animals Bureau, which can be obtained from the Royal Veterinary College, Royal College Street, London, N.W. 1.

Bacteria. Strains used in microbiological chemistry are kept at Teddington (Collection 2) where they are checked not only for purity but also for their activity as agents for microbiological assays. In the same collection are bacteria used in industrial processes such as the production of dextrans, acetone and vinegar.

Bacteria pathogenic for plants are available from Dr W. J. Dowson's comprehensive collection at Cambridge (Collection 3). Human and animal pathogens and related non-pathogenic species can be obtained from the National Collection of Type Cultures at Colindale (Collection 4). The function of this collection is to supply strains that are culturally and serologically typical; it also acts as a repository for strains that are not fully worked out.

Strains of proven toxigenicity, and in which the different toxins have been identified, are kept at Beckenham (Collection 5) and can be obtained in stable form as desiccates.

Leptospira are technically difficult to keep in pure culture; Dr J. C. Broom has kindly offered to meet requests for these cultures from his collection of thirty-six species. Those who want cultures should write to the Director of the Laboratories (Collection 6).

Fungi. Isolates of taxonomic significance, 'syllabus types' for teaching, plant pathogenic species, and fungi used in industry can be obtained from 
Table 1. Culture Collections in the United Kingdom

$\mathbf{1}$

2

3

4

5

6

7

8

9

10

Collection of Algae and Protozoa,

Botany School, Downing Street, Cambridge.

National Collection of Industrial Bacteria, Chemical Research Laboratory, Teddington, Middlesex.

Collection of Bacteria Pathogenic to Plants, Subdepartment of Mycology and Plant Pathology, Botany School, Downing Street, Cambridge.

National Collection of Type Cultures, Central Public Health Laboratory, Colindale Avenue, Colindale, London, N.W. 9.

Wellcome Collection of Bacteria, Wellcome Research Laboratories, Langley Court, Beckenham, Kent.

Wellcome Laboratories for Tropical Medicine, Euston Road, London, N.W.1.

Commonwealth Mycological Institute Collection of Fungus Cultures, Ferry Lane, Kew, Surrey.

Forest Products Research Laboratory, Princes Risborough, Aylesbury, Bucks.

Subdepartment of Medical Mycology, London School of Hygiene and Tropical Medicine, Keppel Street, Gower Street, London, W.C. 1.

Brewing Industry Research Foundation, Lyttel Hall, Nutfield, near Redhill, Surrey.

the Commonwealth Mycological Institute (Collection 7). Antibiotic producing strains are also kept, but the collection does not guarantee that they are in the state of maximum productivity.

The wood-rotting fungi form a highly specialized collection sponsored by D.S.I.R. (Collection 8).

Species pathogenic for man and animals were collected by Dr J. T. Duncan and can be obtained from his successor (Collection 9).

Viruses and bacteriophages. None of the collections maintains viruses or bacteriophages, but the N.C.T.C. can obtain these for experienced workers from specialized laboratories.

Yeasts. Pathogenic yeasts can be obtained from Collection'9, non-pathogenic species from the new Brewing Industry Research Foundation (Collection 10). This collection is not limited to species used by brewers. 


\section{Lists of cultures}

Many of the collections mentioned are preparing catalogues giving details of the strains they maintain, but until these have been printed the gap will be filled by a List of Species appended to a Directory of Culture Collections in the United Kingdom and Crown Colonies. This will be published by His Majesty's Stationery Office on behalf of the British Commonwealth Collections of Microorganisms, an organization set up on the recommendation of a specialist conference (Report, 1947). National committees in each of the Dominions and the United Kingdom have collected information about collections large and small, and within the next few years a series of directories will provide information on microbiological cultures available in the Commonwealth.

\section{REFERENCE}

REPort (1947). Specialist Conference on Culture Collections of Micro-organisms. (S.O. Code No. 47-139.) London: H.M.S.O.

(Received 13 March 1951) 